Cite this: Med. Chem. Commun., 2013, 4, 1105

Received 4th March 2013

Accepted 17th May 2013

DOI: $10.1039 / c 3 m d 00071 \mathrm{k}$

www.rsc.org/medchemcomm

\title{
Exceptionally strong intermolecular association in hydrophobic DNA minor groove binders and their potential therapeutic consequences $\uparrow$
}

\author{
John A. Parkinson, Fraser J. Scott, Colin J. Suckling* and Gail Wilson
}

An antibacterial DNA minor groove binder is shown by NOE experiments to self-associate in aqueous solution at temperatures up to $80^{\circ} \mathrm{C}$ in an anti-parallel, head-to-tail orientation as found in binding to duplex DNA oligomers.

\section{Introduction}

Minor groove binders for DNA have been shown to possess many biological properties, in particular antibacterial activity. ${ }^{\mathbf{1 , 2}}$ One of the most potent series includes molecules based loosely upon the structure of the natural product, distamycin, $\mathbf{1}$, in which the $\mathrm{N}$ terminal formyl group has been replaced by an aromatic ring and one of the amide links replaced by the isosteric alkene as represented by $\mathbf{2 - 4}$. $^{3}$ Compounds $\mathbf{2 - 4}$ are all significantly active against many Gram positive bacteria (MIC in range $0.12-5 \mu \mathrm{M}$ ) and 4 is more effective than vancomycin against many strains of resistant bacteria; $;^{3,4} 4$ is in late stage pre-clinical development. Although the full mechanism of antibacterial activity of these compounds has not been established, there is a strong correlation between DNA binding and antibacterial activity. ${ }^{1,5}$ For example, the naphthyl analogue of 4, 5, is neither significantly active as an antibacterial agent nor a strong binder to DNA oligomers. ${ }^{3}$

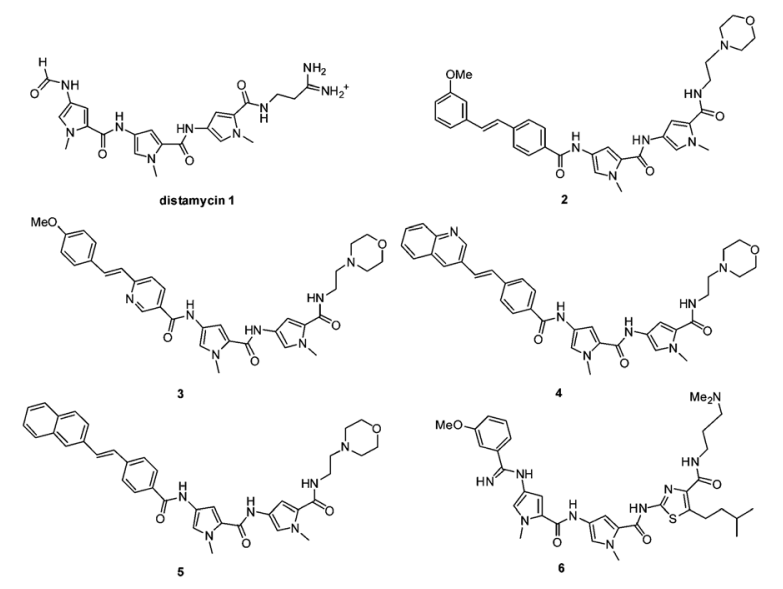

WestCHEM Research School, Department of Pure \& Applied Chemistry, University of Strathclyde, 295 Cathedral Street, Glasgow, G1 1X, Scotland, UK. E-mail: c.j.suckling@strath.ac.uk; Fax:+44 141548 5743; Tel: +44 1415482271

$\uparrow$ Electronic supplementary information (ESI) available. See DOI: $10.1039 / \mathrm{c} 3 \mathrm{md} 00071 \mathrm{k}$
Distamycin and its analogues were first shown to bind in a head-to-tail, anti-parallel mode within the DNA minor groove by NMR studies of a $2: 1$ complex with the non-self-complementary duplex d(CGCAAATTGGC) $\cdot d\left(\right.$ GCCAATTTGCG). ${ }^{6}$ This mode of DNA binding has subsequently been shown to predominate for distamycin-related classes of small molecule. ${ }^{7,8}$ Studies in our laboratory that have used NMR data to confirm structural details agree with this, ${ }^{3,9-14}$ and have attempted to address questions raised about sequence specificity and the thermodynamics of binding. ${ }^{11}$ Thermo-chemical studies of the binding of a number of minor groove binders to DNA and molecular dynamics simulations have suggested that a minor groove binder should associate with DNA from aqueous solution as a pre-formed, self-assembled dimer. ${ }^{13}$ Several types of intermolecular forces can be considered to steer the association of these minor groove binders including hydrophobic interactions, specific hydrogen bonding, face-to-face $\pi$-stacking, $\pi$-cation, and dipole-dipole interactions. Aggregation of ligands in free solution capable of binding to the DNA-minor groove as face-toface dimers have been reported widely in the literature. ${ }^{\mathbf{1 5}}$ However, conclusive experimental proof concerning the detailed structural arrangement of the free-solution associations of the type of ligands concerned in these studies (1-6) has not been reported. Such detailed information would be relevant not only for understanding the DNA binding mechanism but also for tailoring the design and formulation of drug candidates, where aggregation is likely to substantially influence physicochemical properties.

\section{Results}

Investigations of the solution properties of these potent antibiotics were based on 2 , which was selected for study because of its mono-basicity (thereby reducing the potential complexity of ionic states during self-association) and because the structure of its $2: 1$ complex with the DNA oligomer d(CGATATATCG) $)_{2}$ is already known (Fig. S1†).,14 Although 2 is not the most active antibacterial compound of the set, its ${ }^{1} \mathrm{H}$ NMR spectrum is 
sufficiently resolved to permit essentially complete resonance assignment, a requirement when assessing solution structures. For the clinical candidates $\mathbf{3}$ and $\mathbf{4}$ this is not the case. However all three compounds, 2, 3, and 4, have very similar solution behaviour at the macroscopic level so that molecular interactions deduced for 2 can reasonably be extended to 3 and $\mathbf{4}$. For these experiments, the mono-hydrochloride of 2 was prepared from the pure free base by repeated freeze-drying from dilute hydrochloric acid. Its ${ }^{1} \mathrm{H}$ NMR spectrum in aqueous solution $\left(90 \% \mathrm{H}_{2} \mathrm{O} / 10 \% \mathrm{D}_{2} \mathrm{O}, 5 \mathrm{mM}\right)$ at $25{ }^{\circ} \mathrm{C}$ was found to be broad and largely featureless, a characteristic of substantial self-association (confirmed by negative NOEs), and signals were not assignable with any degree of certainty (Fig. S2 $\dagger$ ).

The behaviour of 2 in aqueous solution was subsequently measured as a function of temperature. Although little change in resolution was observed at increasing temperatures, linewidths reduced sufficiently to allow NMR data $\left[1 \mathrm{D}^{1} \mathrm{H}, 2 \mathrm{D}\left[{ }^{1} \mathrm{H},{ }^{1} \mathrm{H}\right] \mathrm{COSY}\right.$, TOCSY, NOESY and $\left.2 \mathrm{D}\left[{ }^{1} \mathrm{H},{ }^{13} \mathrm{C}\right] \mathrm{HSQC}\right]$ to be acquired at $80{ }^{\circ} \mathrm{C}$. These were sufficiently resolved to permit the assignment of some key resonances (Fig. 1). This assignment was partially achieved by monitoring resonance shape and chemical shift at ambient temperature following the sequential addition of

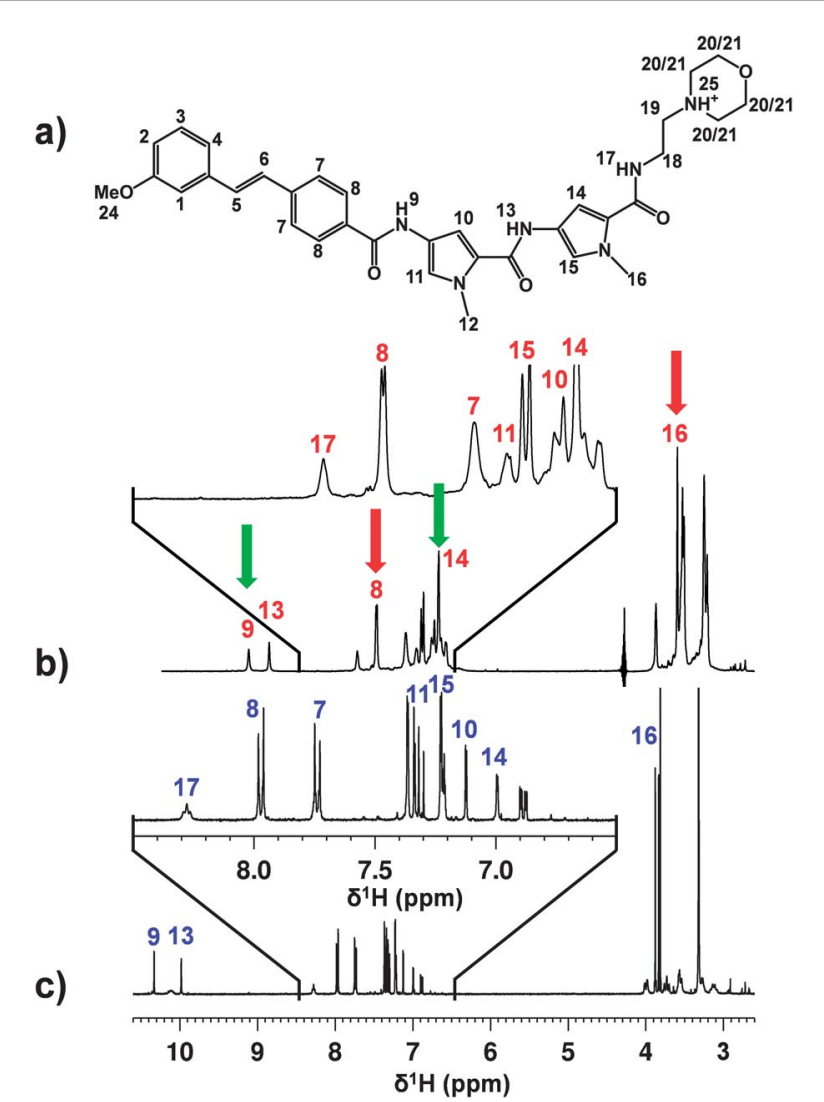

Fig. 1 Assigned ${ }^{1} \mathrm{H}$ NMR data from 2 acquired at $600 \mathrm{MHz}$. (a) Chemical structure of $\mathbf{2}$ with atom numbering used in the data assignment. (b) ${ }^{1} \mathrm{H}$ NMR spectrum of $\mathbf{2}$ in $90 \% \mathrm{H}_{2} \mathrm{O} / 10 \% \mathrm{D}_{2} \mathrm{O}$ at $80{ }^{\circ} \mathrm{C}$. (c) ${ }^{1} \mathrm{H}$ NMR spectrum of 2 in DMSO-d 6 . Expansions are shown for the region $\delta^{1} \mathrm{H}=6.5-8.5 \mathrm{ppm}$. Selective signal assignments are shown for both sets of conditions and coloured differently for the avoidance of confusion. Coloured arrows indicate peaks relevant to intermolecular NOE observations shown in Fig. 2. For full signal assignments see Table S1 in the ESI. $\dagger$ aliquots of DMSO- $\mathrm{d}_{6}$ to aqueous solutions of 2 and making comparisons with fully assigned data for 2 solubilized exclusively in DMSO-d 6 (Fig. 1 and S3†). Several important assignments were conclusively mapped between data acquired for 2 solubilized in both DMSO-d $\mathrm{d}_{6}$ at $25{ }^{\circ} \mathrm{C}$ and water at $80{ }^{\circ} \mathrm{C}$. By this approach ${ }^{1} \mathrm{H}$ NMR resonances Hs8, amide $\mathrm{NH}$, pyrrole $\mathrm{H} 14$, and $\mathrm{N}$-methyl H16 protons were identified. These atoms are located towards either the C-terminus or N-terminus of 2 (Fig. 1a).

Studies of the interactions between drug molecules using one and two-dimensional NMR spectroscopy have been reported in part with the aim of understanding the basis of the therapeutic effects of combinations of drugs in cancer chemotherapy. ${ }^{16-18}$ Subsequent study of the $2 \mathrm{D}\left[{ }^{1} \mathrm{H},{ }^{1} \mathrm{H}\right]$ NOESY NMR spectrum of 2 yielded several identifiable cross-peak assignments which could be mapped onto intra- and inter-molecular interactions (Fig. S4†). Intramolecular NOEs were observed between signals from $\mathrm{H} 13$ and $\mathrm{H} 14$, and between signals for $\mathrm{H} 13$ and $\mathrm{H} 16$ of the $N$-methyl group of the same pyrrole ring. NOEs from H14 and H16 were observed to H17. An NOE response was also observed between NH9 and H8. These observations are consistent with the curved, planar character of 2 and relate to protons close to one another consistent with the covalent structure. More notably, NOE correlations were also observed between $\mathrm{H} 8$ and $\mathrm{H} 16$, and between NH9 and H14. In both instances, these proton pairs are too far separated for intra-molecular NOEs to occur, especially at the short mixing times used in the experiments and accounting for potential spin-diffusion. However, by considering 2 to be predominantly paired as a head-to-tail, face-to-face dimer in aqueous solution, the NOEs can be fully satisfied structurally, thereby providing evidence for intermolecular association of 2 as shown schematically in Fig. 2.

It is of interest to consider whether or not head-to-tail, faceto-face dimerisation is an intrinsic property of 2 and related minor groove binders in the absence of a DNA template. The assembly process was investigated by means of a molecular dynamics simulation. A model of 2 in the form of a pdb file was prepared and imported into the AMBER molecular modelling software package and solvated using an explicit box of water. ${ }^{19}$ The assembly of molecules was energy-minimised, run under

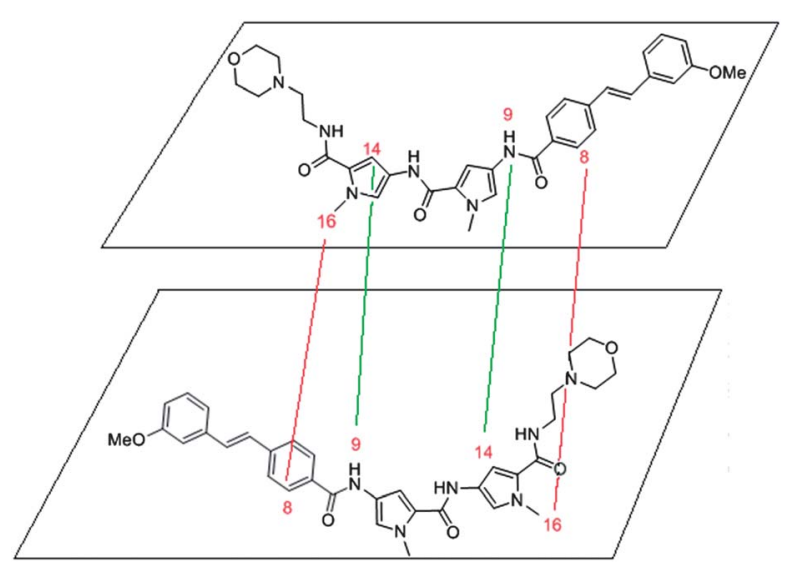

Fig. 2 Proposed structure of dimer of $\mathbf{2}$ interpreted from NOE spectrum. The coloured lines match the coloured arrows in Fig. 1. 
MD conditions by first equilibrating and then running under production conditions according to standard protocols developed at Strathclyde for investigating ligand binding to duplex DNA in the minor groove. ${ }^{11}$ Within 50 ps of the production run starting, the two molecules of 2 were observed to interact, very swiftly forming a dimer consistent with the structure deduced from the experimental NMR data. The dimer remained assembled in this form for the remainder of the production run without dissociation (Fig. S5 and video clip $\dagger$ ).

\section{Discussion}

Aggregation of 2 as head-to-tail, face-to-face dimers is consistent with several observations. Firstly, pre-association as a dimer in dilute aqueous solution would support a low dissociation constant for 2 and its DNA target. Indeed values in the range 1-10 $\mathrm{nM}$ are typical for minor groove binders in the Strathclyde library. ${ }^{13}$ Secondly, in the series containing alkene linkages represented by $\mathbf{2 - 4}$, unusually low $\mathrm{p} K_{\mathrm{a}} \mathrm{s}$ for the morpholinoethyl group have been measured, a feature that is explained by the self-association (Table 1). Notably, the minor groove binder $\mathbf{6}$, which is also antibacterial, has more normal $\mathrm{p} K_{\mathrm{a}} \mathrm{s}$ for both of the basic functional groups. Thirdly, whilst the solubility of 2-4 is high at $\mathrm{pH}$ less than $4\left(>100 \mathrm{mg} \mathrm{mL}^{-1}\right)$, as the $\mathrm{pH}$ was raised to between 4 and 5 , all three compounds formed gels over a period of 30 minutes to several hours. Gel formation was retarded by the addition of excipients such as mannitol, hydroxyethyl- $\beta$-cyclodextrin and especially glucose 6-phosphate but could not be avoided. These results, including the appearance of the NMR spectra at or near room temperature, are strongly suggestive of extended dimer aggregates.
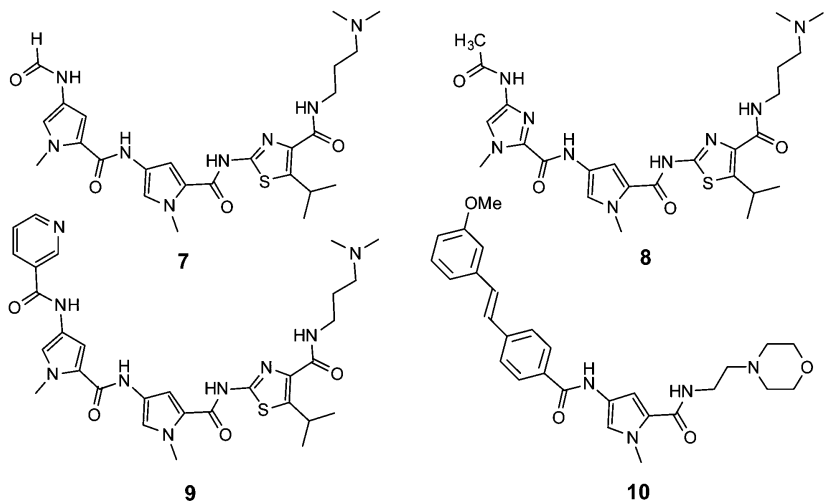

The exceptional aggregation characteristics of 2 may be put into their full context by comparing these results with those recorded for a range of related compounds that aggregate to lesser but varying degrees. 9 self-assembles with an association constant, $K_{\text {ass }}=6.1 \times 10^{4} \mathrm{M}^{-1}$ that was determined by NMR

Table 1 Measured $p K_{a}$ values of antibacterial minor groove binders

\begin{tabular}{lllll}
\hline Compound & $\mathbf{2}$ & $\mathbf{3}$ & $\mathbf{4}$ & $\mathbf{6}$ \\
\hline $\mathrm{p} K_{\mathrm{a}} 1$ & $\mathrm{NA}$ & 3.49 & 4.38 & 8.44 \\
$\mathrm{p} K_{\mathrm{a}} 2$ & 6.04 & 5.26 & 6.02 & 9.12
\end{tabular}

spectroscopy. ${ }^{13 b}$ Without the nicotinamide headgroup (compounds 7 and 8), $K_{\text {ass }}$ is lower by an order of magnitude (i.e. $10^{3} \mathrm{M}^{-1}$ ). This is reflected qualitatively by the ${ }^{1} \mathrm{H}$ NMR spectrum linewidths and NOE responses observed: when association is weaker, linewidths are much narrower and the NOE response is either weak or absent. 10, a truncated form of 2, gives narrower (relative to 2) but resolved ${ }^{1} \mathrm{H}$ NMR resonances at room temperature and strong negative NOEs. Based on the similarity between data for $\mathbf{1 0}$ and that of $\mathbf{9}$, we expect $K_{\text {ass }}$ for $\mathbf{1 0}$ to be of the order of $10^{4}$ to $10^{5} \mathrm{M}^{-1}$ according to our preliminary diffusion measurements. The ${ }^{1} \mathrm{H}$ NMR linewidths for 2 are almost twice those of $\mathbf{1 0}$ (Fig. S6 $\dagger$ ) suggesting a $K_{\text {ass }}$ of the order of at least $10^{5} \mathrm{M}^{-1}$. We are currently attempting to quantify the self-association of these compounds as part of a wider study, the results of which shall be reported in due course.

With respect to their application as antibacterial drugs, dimer formation and extended aggregation have substantial consequences. Several experimental studies using a range of physical methods including NMR and a molecular modelling have demonstrated the association of drug molecules with a high degree of planarity and consequentially lowered bioavailability and cell penetration. ${ }^{16-18}$ One such study concerned minor groove binders of a different class (terbenzimidazoles) from the Strathclyde library of distamycin derivatives, in which higher cellular activity was associated with lower aggregation. ${ }^{17}$ All these studies, however, investigated combinations of drugs with significant anti-cancer activity. The antibacterial activity of 2-4 is limited by their cell penetration. All have significant activity against a wide range of Gram positive bacteria but are essentially inactive against Gram negative bacteria.,9 The fluorescence of these diarylalkenyl minor groove binders has made it possible to demonstrate that they do not accumulate in Gram negative bacterial cells. Together, these results imply that 2-4 do not enter Gram negative bacterial cells, an observation that is most likely associated with their large size as dimers. The probability that a compound with these physicochemical characteristics will be an orally active bioavailable drug has been estimated at about $5 \%$ by evaluating a data set of 100000 compounds $^{20}$ and indeed the formulation of the most active compound and clinical lead, $\mathbf{4}$, is a challenge because of gelation above $\mathrm{pH} 4$. However, for the initial intended use, these properties can be turned to advantage. In studies of oral bioavailability in hamsters for the treatment of Clostridium difficile infections in the gastro-intestinal tract, it has been found that negligible quantities (18-263 $\mathrm{ng} \mathrm{mL}^{-1}$ ) of minor groove binder 4 were detectable in plasma leaving the vast majority of the dose available to treat the infection. ${ }^{21}$

\section{Conclusions}

Strong dimerisation in dilute aqueous solution has been demonstrated for alkene-containing minor groove binders exemplified by $\mathbf{2 - 4}$. The effect of dimerisation is manifested in the formulation and bioavailability of the most active compound $\mathbf{4}$, but with careful attention to formulation and dosing, $\mathbf{4}$ has been shown to have great promise as a treatment for resistant Gram positive bacteria, in particular Clostridium difficile. $^{21}$ 


\section{Notes and references}

1 C. J. Suckling, J. Phys. Org. Chem., 2008, 21, 575-583.

2 C. J. Suckling, Future Med. Chem., 2012, 4, 971-989.

3 C. J. Suckling, D. Breen, A. I. Khalaf, E. Ellis, I. S. Hunter, G. Ford, C. G. Gemmell, N. Anthony, J.-J. Hélèsbeux, S. P. Mackay and R. D. Waigh, J. Med. Chem., 2007, 50, 6116-6125.

4 M. Ravic, C. J. Suckling, C. G. Gemmell and I. S. Hunter, Abstract 1438, 22 $2^{\text {nd }}$ European Congress of Clinical Microbiology and Infectious Diseases, London, England, 2012.

5 A. I. Khalaf, R. D. Waigh, A. J. Drummond, B. Pringle, I. McGroarty, G. G. Skellern and C. J. Suckling, J. Med. Chem., 2004, 47, 2133-2156.

6 J. G. Pelton and D. E. Wemmer, Proc. Natl. Acad. Sci. U. S. A., 1989, 86, 5723-5727.

7 D. E. Wemmer, Biopolymers, 2001, 52, 197-211.

8 S. Neidle, Nat. Prod. Rep., 2001, 18, 291.

9 N. G. Anthony, K. R. Fox, B. F. Johnston, A. I. Khalaf, S. P. Mackay, I. S. McGroarty, J. A. Parkinson, G. G. Skellern, C. J. Suckling and R. D. Waigh, Bioorg. Med. Chem. Lett., 2004, 14, 1353-1356.

10 J. A. Parkinson, A. I. Khalaf, N. G. Anthony, S. P. MacKay, C. J. Suckling and R. D. Waigh, Helv. Chim. Acta, 2009, 92, 795-822.

11 H. Y. Alniss, N. G. Anthony, A. I. Khalaf, S. P. MacKay, C. J. Suckling, R. D. Waigh, N. J. Wheate and J. A. Parkinson, Chem. Sci., 2012, 3, 711-722.

12 N. G. Anthony, B. F. Johnston, A. I. Khalaf, S. P. MacKay, J. A. Parkinson, C. J. Suckling and R. D. Waigh, J. Am. Chem. Soc., 2004, 126, 11338-11349.

13 (a) W. Treesuwan, K. Wittayanarakul, N. G. Anthony, G. Huchet, H. Alniss, S. Hannongbua, C. J. Suckling, J. A. Parkinson, R. D. Waigh and S. P. Mackay, Phys. Chem.
Chem. Phys., 2009, 11, 10682-10693; (b) M.-V. Salvia, F. Addison, H. Y. Alniss, N. J. Buurma, A. I. Khalaf, S. P. Mackay, N. G. Anthony, C. J. Suckling, M. P. Evstigneev, A. H. Santiago, R. D. Waigh and J. A. Parkinson, Biophys. Chem., 2013, 179, 1-11.

14 N. G. Anthony, D. Breen, G. Donoghue, A. I. Khalaf, S. P. Mackay, J. A. Parkinson and C. J. Suckling, Org. Biomol. Chem., 2009, 7, 1843-1850.

15 B. A. Armitage, Top. Curr. Chem., 2005, 253, 55-76.

16 D. B. Davies, M. P. Evstigneev, D. A. Veselkov and A. N. Veselkov, Biophys. Chem., 2005, 117, 111-118.

17 A. N. Veselkov, M. P. Evstigneev, A. O. Rozvadovskaya, A. Hernandez Santiago, O. V. Zubchenok, L. N. Djimanta and D. B. Davies, J. Mol. Struct., 2004, 701, 31-37.

18 Q. A. Khan, C. M. Barbieri, A. R. Srinivasan, Y.-H. Wang, E. J. LaVoie and D. S. Pilch, J. Med. Chem., 2006, 49, 52455251.

19 D. A. Case, T. A. Darden, T. E. Cheatham, III, C. L. Simmerling, J. Wang, R. E. Duke, R. Luo, R. C. Walker, W. Zhang, K. M. Merz, B. Roberts, B. Wang, S. Hayik, A. Roitberg, G. Seabra, I. Kolossvai, K. F. Wong, F. Paesani, J. Vanicek, J. Liu, X. Wu, S. R. Brozell, T. Steinbrecher, H. Gohlke, Q. Cai, X. Ye, J. Wang, M.-J. Hsieh, G. Cui, D. R. Roe, D. H. Mathews, M. G. Seetin, C. Sagui, V. Babin, T. Luchko, S. Gusarov, A. Kovalenko and P. A. Kollman, AMBER 11, University of California, San Francisco, 2010.

20 R. Y. Young, D. V. S. Green, C. N. Luscombe and A. P. Hill, Drug Discovery Today, 2011, 16, 822-830.

21 M. Ravic, C. J. Suckling, C. G. Gemmell, P. Warn, M. Saunders, Abstract $52^{\text {nd }}$ Interscience Conference on Antimicrobial Agents and Chemotherapy, San Francisco, USA, 2012. 